\title{
The Effect of Marketing Communications on the Sales Performance of Ghana Telecom (Vodafone, Ghana)
}

\author{
Nana Yaa Dufie Okyere \\ Nyakams Limited, Box, KN 1429, Accra, Ghana \\ E-mail: nanayaaokyere@ymail.com \\ Gloria K.Q Agyapong (Corresponding author) \\ School of Business, University of Cape Coast, Cape Coast, Ghana \\ E-mail: ritegloria@yahoo.co.uk \\ Kwamena Minta Nyarku \\ School of Business, University of Cape Coast, Cape Coast, Ghana \\ E-mail:k_nyarku@yahoo.com
}

Received: April 19, $2011 \quad$ Accepted: June 27, $2011 \quad$ Published: November 1, 2011
doi:10.5539/ijms.v3n4p50

\begin{abstract}
One of the problem areas in marketing of great practical and theoretical significance about which much remains to be learned is the nature of market response to a firm's marketing mix. Marketers are therefore concerned about the coordination between communications and their sales and the expenses thereof. This study sought to examine the relationships existing between marketing communications activities and the sales performance of Vodafone. The study also made use of simple statistical tools such as tables, graphs, together with multiple regression analysis to determine the degree of variation between the dependent (sales volume) and independent variable (communication tools). The results indicated strong relationships between sales promotion, advertising budgets and total sales. There was however an inverse relationship between TV advertisements and sales. In addition, a negative relationship was also found to exist between sponsorship budget and total sales. The outcome indicates that Vodafone was not paying much attention to its total communication costs and the return on investment (ROI) on such expenditures. It is recommended therefore that management and other marketers in the industry regularly evaluate the marketing communications activities they engage in as this will inform them on how effective their communications activities are and what returns to expect on these marketing communications activities.
\end{abstract}

Keywords: Marketing communications, Sales performance, Marketing mix, Return on investment

\section{Introduction}

Most business organizations operate in a complex and competitive environment where demands are constantly changing. To confront this challenge, management of business organisations have had to increase the levels of resources with attention focused on attracting and retaining customers. This situation has prompted the marketing concept that Kotler (1988) describes as the determination and subsequent satisfaction of customer needs and wants more efficiently and effectively than one's competitors. In this era of intense competition, especially within the telecommunication sector, the criterion for measuring success would much depend, on creating awareness, persuasion and informing customers of the existence of offerings. This has however resulted in several marketing communications tools being employed by marketers to help them succeed in this game of competition. Telecom organizations generally, and GT (Vodafone) specifically, are managing their marketing communications activities in an integrated manner, with the coordination of message, media and timing, developed in support of the overall organizational objectives.

The most essential aspect of any business is selling their brand(s) since sales sustain any business' existence. Selling, as a marketing function, involves promoting the product. This entails the use of personal selling, and 
advertising, including other direct mass-selling methods. Perhaps, this is the most visible aspect of marketing. Invariably, sales must necessarily begin with some form of awareness creation. However to build sales, promotion must be seen or heard by potential buyers and cause them to react to the information in some way desired by the marketer. In order to elicit this desired action, Palmer (2005) posits that the message is presented according to a simple "master formula" (model) which is: Attract the "attention" of your prospect; "Interest" your prospect in the product; cause your prospect to "desire" the product, and demand "action" from the prospect. This is known as the AIDA concept, one of the numerous models adopted by marketing practitioners. This implies that getting the prospect's attention is marketing communications first task. For instance, if an advertisement does not gain attention, it does not matter how many people see or hear, it would yield no positive impact on the business. However, many attention-getting devices such as a large headline, computer animations, news or shocking statements, attractive models, babies, animals, special effects are now available. In short, anything different or eye-catching may do the trick. Indeed, catching and holding the interest of the prospect is much more difficult than could be imagined. To sustain interest, every communication needs to speak the target audience's language. In addition, every communication must also provide evidence to convince the customer that a particular brand is the best choice. Churchill Jr. \& Peter (1998) maintain that arousing the prospect's desire to buy a particular product is one of marketer's most difficult tasks. An advert, for instance, must convince customers that the product can meet their needs. Getting the prospect's action is the final requirement and definitely not an easy task. Prospective customers must be led beyond considering how the product might fit into their lives but to actually trying it or allowing for product demonstration. For instance, an advertisement that includes a toll-free telephone number might prompt prospects that are not yet ready to buy to at least call the number for more information. Arens (1999) emphasizes that appealing to important needs can get more action and provide the kind of information buyers need to confirm their decisions. In a general sense, to obtain optimum results from promotions, the activities must highlight strongly felt customer needs that can only be uncovered through careful research.

Over \$245 billion was spent on advertising alone in the United States in 2003, (Advertising Age, 2005). According to a report by PricewaterhouseCoopers (2005), a global accounting firm, the worldwide advertising spending rose to $\$ 385$ billion. They projected that spending is likely to exceed half a trillion dollars by 2010 . A similar study conducted by Ernst \& Young (1996) indicates that promotional expenditure on leading branded goods represent between 7 and 10 per cent of sales revenue. In spite of the enormous levels of spending, an important economic question is yet to be resolved: is there a significant relationship between marketing communications expenditure and sales as registered in volumes? Several years of academic research investigating this relationship and future demand has yielded inconclusive findings. Much as promotion is considered necessary for the growth and survival of a business, its influence on a firm's budget cannot, however, be overlooked. Promotional expense therefore can no longer be regarded as just a current expense but rather an investment. If it is, then managers must ensure that the returns on such investments bear positively on their sales performance and the business in entirety.

The phases of change in the telecommunication industry in the world generally, and in Ghana particularly have had significant toll on Vodafone's operations. Changes such as its divestiture, with the break-down of its absolute control over all phases of providing telephone service (monopoly) coupled with increased competition have shifted Vodafone's focus to being more 'consumer' or 'market' oriented. The change has primarily been due to the entry of other service providers into the industry culminating in the introduction of a variety of new services in the telecom industry. This has resulted in lots of creative promotional activities going on with advertising and sales promotions apparently topping these campaigns in recent times. This development is however posing financial challenges to firms. Most organizations are for example, concerned about the spiralling costs of trade promotional expenditure, while having very little understanding of their return on investment at the same time. Despite the huge investments and the concerted efforts in marketing communications, many are not successful. Often, the effects are uncertain and sometimes take a long time to make an impact on a customer's behaviour. This is the more reason why firms sometimes consider reducing expenditure or eliminating promotions from their budget altogether, especially as a cost cutting measure during financial crises. Such is the case, when their brands appear to be doing well and their market-share appears to be expanding.

Perhaps creating awareness of a firm's product(s) and subsequent purchase is essential for most organizations' success and long-term growth. One key challenge confronting most trading firms, Ghana Telecom (GT) (Vodafone) being no exception, is how to measure and evaluate the impact of their integrated marketing communication efforts on their business performance as a whole. The evaluation of sponsorship's effectiveness, for example, seems to be the most challenging aspect of the marketing communications efforts as sponsorship 
authors such as Fahy, Farrelly and Quester (2004); Chadwick and Thwaites (2004); and Stotlar (2004), highlighted The basic question then is whether the firms engaged in these activities are getting the required returns from the huge financial commitments into such activities. The main objective of this study is to find out if GT's (Vodafone) budgetary commitment in marketing communications is registering significant effects on the sales volumes of its products.

\section{Review of Literature}

Eberhard and Lenz (2006) opine that the saturation of the international mobile telecommunication markets and the appearance of new competitors are increasing the importance of the communication aspects of selling mobile brands. In other words, with more and more markets are reaching a saturation point, coupled with the increasing homogeneity of mobile services, telecom firms are depending more on marketing communications and segmenting specific offers to create differentiation in their offerings. Even though telecom firms are expected to continuously work on product innovations, the real differentiation by competitive relevance will only be possible by using targeted communication planning and campaign management. Invariably, brands and communication are the link between the company and the customer, giving the latter the opportunity to distinguish one brand from another. Meanwhile, marketers are always looking for prospects. These prospects are individuals, household, or organizations that a marketer thinks might be turned into customers. Customers in turn are those people who actually buy. Similarly, a consumer is another term often used to describe members of a market. Precisely, these people actually use a product or service. In this sense, the challenge for the marketer is to focus on factors that matter most to customers. The key to success therefore, is to look at everything from the customer's perspective. In short, marketing means taking into consideration what customers need and want, how they make decisions about how to satisfy their needs, and so on, and then doing something with that knowledge. For instance, a typical decision to provide wireless phone should be based on the customer's need to talk to people when on the move.

Grasby et al (2000) argue that marketing is much more than simply selling what the company makes or advertising what the company has. They emphasize that it is rather about deciding what to do and for whom. In practice, marketing should lead the firm's strategy towards making what can be sold, not selling what can be made. The American Marketing Association (AMA) (2008) has provided a clearer definition of marketing as an organizational function and a set of processes for creating, communicating, and delivering value to customers and for managing customer relationships in ways that benefit the organization and its stakeholders. AMA (2008) redefined marketing as the process of planning and executing the conception, pricing, promotion and distribution of ideas, goods, services, organizations and events to create and maintain relationships that satisfy individual and organizational objectives. Even though both definitions highlight the importance of the management of relationships in marketing operations, the latest definition, however, places emphasizes on the marketing mix (4Ps - product, price, place and promotion). In addition, Cowell (1994) provides another dimension explaining marketing as the way in which an organization matches its own human, financial and physical resources with the wants of its customers. Similarly, the Institute of Marketing has defined marketing as the management process responsible for identifying, anticipating and satisfying customer requirements profitably.

It could be inferred from these definitions that the concept of marketing is to simply create, win and to keep a prospect to be turned into a customer. To do this however, the organization has to create, produce, and deliver the products that the prospects want and value. To ensure the continuity of these activities, the organization, if it is a profit-making venture, must generate revenue that exceeds the costs, is of sufficient size and is generated regularly to attract, keep and develop capital for the organization to keep abreast if not ahead of competitive offerings. For the purpose of this study, a practical definition of marketing is given as the number of actions undertaken to elicit desired responses from a target audience. The actions referred to in this definition must definitely be conveyed to the consumer through a medium referred to as communication.

\subsection{Theories of Communication}

Communication plays a vital role in the fulfilment of all the above marketing objectives. Understanding communication is essential since it is the basic process through which managers specifically and organizations in their entirety accomplish their set objectives culminating in their success. Smith, Berry and Pulford (1997) describe communication as the act of sending information from the mind of one person to the mind of another person. Similarly, Churchill Jr. and Peter (1998) describe communication as the transmission of a message from a sender to a receiver, such that both understand it the same way. Mcshane and Glinow (2000) in turn, define communication as the process by which information is transmitted and understood between two or more people. 
These descriptions together emphasize the fact that effective communication involves a sender and a receiver, and the transmission of a message from one person to another including the sharing of meaning between parties purported to be communicating. Communication can simply be explained to take place in the form of a message that is exchanged between a source and receiver. For example, a print advertisement, coupon, television commercial, or any communication activity must be created to clearly convey the intended meaning of the organization to its targeted audience. Communication identifies a number of concepts and relationships that are of importance to the marketer: As an interpersonal activity, communication is dependent on the social context in which it takes place, and the person sending the information will do so in a variety of ways, all at the same time. In addition, the sender will also need to identify in advance the person to whom the message is being sent, and will therefore need to know how the receiver (the audience) will interpret it. For instance, a sharing relationship must exist between sender (an advertiser, for instance) and receiver (the consumer). The sender will also need to see evidence that the message has not only been received but also clearly understood. It is important to stress that the sender will need to persuade the receiver that the message is worth listening to, besides the message itself being in a form of language that the receiver can understand. In all these, there should be clear and obstructed route or channel through which the message can be sent, and through which the receiver can indicate that the message has been received and understood. Besides, the message will need to be recognised through the distractions (noise) in the channel, and the feedback will need to be interpreted correctly.

The role of communications in a firm's marketing operations can be measured from diverse perspectives because firms not only create awareness among consumers of their brands, but also use communication as a tool to build strong image for their brands. For marketers, it is not good enough to just produce the products or services. Communicating its virtues to the prospective target market is of prime importance. The primary task of the marketer then is to let both actual and potential prospects know that a specific brand exists and to keep its brand name uppermost on the minds of consumers. This invariably generates customer trail and higher customer demand, while facilitating possible increases in returns in the current and future periods. For effective communication to occur, Dubrin (1997) stipulates that six components must be present: a communication source or sender, a message, a channel, a receiver, feedback and the environment.

First, the source (sender) is the initiator of a communication event who is usually a person attempting to send a spoken, written, sign language, or nonverbal message to another person(s). Here, the perceived authority and experience of the sender are important factors influencing how much attention the message will receive.

The second component is the message, which is the purpose or idea to be conveyed. Many factors influence how a message is received. Among them are clarity, the alertness of the receiver, the complexity and length of the message, and how the information is organized.

The third is the channel (medium). This concerns the way the message is transmitted. In organizations, several channels or media are usually available. More often than not, messages are either written or spoken or a combination of the two. In addition, nonverbal cues such as a smile and body gestures accompanies most spoken messages. For example, there is heavy reliance on electronic transmission of messages (email) in today's business environment.

The fourth is the receiver, who is the other party for whom the message is intended. Communication can only be deemed to be complete when the receiver receives the message and understands it properly.

There is also the feedback, which is a message/response sent back from the receiver to the sender. Without feedback, it is difficult to know whether a message has been received and understood. Thus, if the receiver takes action intended by the sender, the message is deemed to have been received satisfactorily.

Finally, there is the environment component. A full understanding of communication requires knowledge of the environment in which messages are transmitted and received. For example, the organizational culture is a key environmental factor that influences communication. It is important also to mention that distractions have a pervasive influence on the components of the communication process. In this context, noise is anything that disrupts communication, including the attitude and emotions of the receiver. Noise includes work stress, fear, ambivalence, blurred visibility and strong advocacy for an opposing position.

Similarly, Jobber (2007), describe a simple model of the communication process as the source (communicator) encoding a message by translating the idea to be communicated into a symbol consisting of words, pictures and numbers. The message is then transmitted through a media such as television or posters, which are selected for their ability to reach the desired target audience in the desired way. Noise such as distractions and distortions during the communication process may prevent transmission to some of the target audience. A television advertisement, for instance, may not reach a member of a household because of a conversation or the telephone 
ringing. When a receiver sees or hears the message, it is decoded. The receiver then interprets the message in the way intended by the source. In this sense, new brands will take time to establish their credibility, and the launch campaign will need to focus on this. Feedback, affords the source a way of monitoring how accurately the intended message is being received. It also allows the source to determine whether the original message hit the target accurately or whether it needs to be altered to evoke a clearer picture in the receiver's mind. The feedback mechanism, perhaps offers the source some measure of control in the communications process.

It is important to note that a receiver, may, sometimes completely misinterpret the message and appear to receive an idea quite different from the one that the sender intended to communicate. This suggests that communication plays a critical role in modern marketing and must be efficiently and effectively managed to enhance a brand's success. The importance of communication in marketing today cannot, therefore, be overemphasized. Shimp (2000) sums it thus, "marketing in the 1990s is communication and communication is marketing," making both inseparable.

Also, Smith et al (1997) identify four communication components as the basic model for transferring an idea from the mind of one party to another: a sender of a message; a receiver of a message; a message passing from a sender to a receiver. This model suggests that the receiver must be aware that a message is being sent to him/her, and from whom. This implies that the credibility of the sender will affect how much attention is paid to the message being transmitted. If credibility is high, the intended receiver will invariably give it attention and believe it. Establishing sender credibility in the target market is a key part of the marketer's role in getting effective messages across, and this is especially important with new brands. Established brands will normally have credibility already built into them, often over many years of advertising and development. Compared with personal communications, businesses operate on a much larger scale and therefore require a wider scope of communication. According to Lucas (1996), most of the monitoring by marketers, is non-personal, quantified feedback and often consist of statistical data that needs to be analyzed and interpreted. Sales might for instance increase during an advertising campaign, but the analysis of the sales data will be required before a connection can be made between the two events, and that means eliminating other factors that might have caused the increase, such as seasonality. Some feedback is easier and faster to analyze, as with coupons redeemed in a below-the-line promotion.

\subsection{Conceptual Framework}

The framework for the study was adopted and modified from Smith et al (1997). The figure illustrates the relationship between marketing communications and business strategy.

\section{Insert Figure 1}

The figure indicates that in integrating the communications model into the overall business strategy, all levels of mangers must play their respective roles to achieve results in their areas of operations. The model is not only about planning and encoding marketing communications messages, but also about the strategic direction of the entire business. Information is gathered and analysed, the communication decision is formulated, encoded and transmitted as messages and mediums such as coupons, raffle draws, radio and TV broadcasts. The target audience or receivers decode the message transmitted. Responses are captured in the form of sales value and volume, complaints received, repeated purchases, switch intent, customer loyalty and customer referrals becomes the feedback from customers to the firm. The feedback is put together, analyzed to produce market data. This is stored for corporate analysis culminating into market analysis to guide management in strategy and policy formulation, ultimately reflecting the marketing communications decisions crafted within the firm.

\subsection{Marketing Communications Tools}

Marketing firms use various tools of communication to promote their offerings in order to achieve their promotional objectives under the marketing mix. According to Kotler and Keller (2009), the marketing communications mix consists of six major modes or channels, even though other authors list more. These are: advertising, sales promotion, publicity and public relations, personal selling, direct marketing, events and experiences (sponsorship). This list although not exhaustive, is not in any order of priority, since different organizations place emphasis on different communication tools. However, this paper considers the six major elements of marketing communications as encapsulated by Kotler and Keller (2009).

\subsubsection{Advertising}

Advertising is one of the elements of the promotion mix which is considered prominent in the overall marketing mix. This attribute is as a result of its visibility and pervasiveness in all the other marketing communication elements. Advertising is any paid form of non-personal presentation and promotion of ideas, goods or services 
by an identified sponsor (where the source is the sponsoring organization) (Kotler \& Armstrong, 2010). For example, in the case of GT (Vodafone), advertising budgetary allocations increased from GH $\phi 4,600,000$ in 2005 to $\mathrm{GH} \phi 5,600,000$ in 2006, $\mathrm{GH} \phi 9,200,000$ in 2007 and decreased to $\mathrm{GH} \phi 6,000,000$ in 2008 (Ghana Telecom Annual Reports, 2005 - 2008).

\subsubsection{Sales Promotion}

Sales promotions are short-term incentives to encourage the purchase or sale of a product. Blythe (2006) describes sales promotion as any activity intended to generate a temporary boost in sales. This includes several communications activities pursued in an attempt to provide added value or incentives to consumers, wholesalers, retailers, or other organizational customers to stimulate immediate sales. Such efforts are usually geared towards stimulating product interest, trial, or purchase. It is specifically designed to boost quick sales and ultimately create loyalty.

\subsubsection{Publicity and Public Relations}

Publicity is the disseminating of information by personal or non-personal means, which is not directly paid for by the organization, nor is the organization the source. Grasby et al (2000) describe publicity as the use of the media to provide free coverage in their stories related to their product. Unlike advertising that relies on purchasing power to get a message across, publicity relies solely on the quality of content to persuade others to get the message out.

Public relations (PR), on the other hand is the overall term for marketing activities that raise the public's consciousness about a product, an individual or issue. Shimp (2000) explains PR simply as an organizational activity involved with fostering goodwill between a company and its various publics. Research has indicated that promotional budgets have recently increased tremendously. In Ghana, budgetary allocations on promotions have equally risen steadily over the years. In contrast with current trends however, GT's (Vodafone), expenditure on Public relations has been recording a declining trend from $\not 780,000$ in 2005 to GHф600,000 in 2006, GH $\phi 500,000$ in 2007, and rising to GH $\phi 184,000,000$ in 2008 (Ghana Telecom Annual Reports and Budget Statements 2005-2008). On the contrary GT's (Vodafone) sales and marketing expenditure rather increased from $\mathrm{GH} \notin 9,080,000$ in 2005 to $\mathrm{GH} \phi 12,700,000$ in 2006, then to $\mathrm{GH} \phi 14,800,000$ in 2007 and $\mathrm{GH} \phi 18,284,000$ in 2008. These huge investments connote that businesses generally and GT (Vodafone) particularly have appreciated the effectiveness of communications on their marketing efforts.

\subsubsection{Personal Selling}

Personal selling which involves personal contact is gradually becoming the backbone of service marketing organizations such as GT (Vodafone). If promotion is communicating with potential customers, then, personal selling is perhaps the best way to do it. Kotler (2006) defines personal selling as face-to-face interaction with one or more prospective purchasers for the purpose of making presentations, answering questions, and procuring orders. Jobber (2007) also describes personal selling as the marketing task that involves face-to-face contact with a customer. Unlike the other tools of the communication mix, personal selling permits a direct interaction between buyer and seller. This two-way communication means that the seller can identify the specific needs and problems of the buyer and tailor the sales presentation in the light of this knowledge.

\subsubsection{Sponsorship}

Since traditional media have become more expensive, sponsorship is viewed by marketers as a cost-effective alternative, (Lee et al., 1997). Events and experience or sponsorship is another marketing communications tool comprising company-sponsored activities and programmes designed to create daily or special-related interactions. In other words, a company can build its brand image through creating or sponsoring events. According to Arens (1999), sponsorship is a cash or in-kind fee paid to a property (which may be a sports, entertainment, or non-profit events or organization) in return for access to the exploitable commercial potential associated with that property. Palmer (2005) describes Sponsorship as getting involved and/or investment in events or causes in order that an organization can achieve objectives such as increased awareness levels, enhanced reputation, etc. GT's (Vodafone) sponsorship programme include sporting activities such as Ghana's Premier League and the sponsorship of specific radio and television programmes, donations to charitable institutions, traditional festivals, and scholarship awards.

\subsubsection{Direct Marketing}

Direct marketing specifically ensures sending a promotional message directly to consumers rather than via a mass medium. It is aimed at creating and exploiting a direct relationship between producers and their customers. The Direct Marketing Association (DMA) has defined direct marketing as an interactive system of marketing 
that uses one or more advertising media in acquiring a measurable response and/or transaction at any location. Similarly, direct marketing is described as the use of mail, fax, e-mail, or internet to communicate directly with or solicit response or dialogue from specific customers and prospects (Kotler \& Keller 2006; Kotler \& Armstrong, 2010).

Table 1 below shows a comparison of revenue generated through normal/regular sales together with sales backed by promotions. The incremental contribution arising from sales promotion campaign of prepaid cards (Easyfone) launched by GT (Vodafone) at the close of 2006 to the beginning of 2007. The data clearly illustrates increased usage although at a decreasing rate during the period of the promotion.

\section{Insert Table 1}

From the table, whereas normal sales without any promotional activity amounted to $\mathrm{GH} \phi 217,508$, promotional sales yielded $\mathrm{GH} \phi 254,100$ giving rise to a $17 \%$ incremental difference of $\mathrm{GH} \phi 36,192$. However, during the last two months of the promotion, the percentage increase of $18 \%$ between normal and promotional sales recorded diminishing returns. Even though the final month recorded an increase, it was less than proportionate percentage increase in sales. The relationship expressed above highlights the conclusions of the work of Sturgess and Young (1981) which deduced that the overall ranges of advertising expenditures response is characterized by diminishing returns. Hence, successive increments in advertising usually stimulated less than proportionate increases in sales.

\section{Methodology}

\subsection{Introduction}

This section is devoted to shedding light on the method adopted for the study. The section begins with the specification of the model followed by the data type as well as the data sources.

\subsection{Model Specification}

The model is designed in a way to test the effect of marketing communication on the sales volume of GT (Vodafone) from January 2006, to December 2008. The number of observations used for the study was 40 derived from GT's (Vodafone) sales records and promotions within the period cited. According to (Hyndman and Kostenko, 2007) forty cases are enough to estimate ordinary regression especially for two/three variable regression. The study adopted a similar method used by Ifeanyi-Obe, Lemchi and Isife, (2008). In that study, company data, which is sales records and promotion periods including budgets were used in evaluating the effect of promotions on sales, with the aid of simple statistical methods such as percentages, tables and charts/graphs. In addition to these descriptive statistical tools, the present study used a multiple linear regression analysis to determine the degree of variation of the dependent variable on the explanatory variable. In following Ifeanyi-Obe et al (2008), and the theoretical positions in Shimp (2000), we state the model in an implicit form as follows:

$$
S V=f(r, s p, \text { spromo, } T V \mathrm{exp})
$$

In an econometric form, the model is stated as:

$$
S V=\alpha_{0}+\alpha_{1} r+\alpha_{2} S p+\alpha_{3} S p r o m o+\alpha_{4} T V e x p+\varepsilon_{t}
$$

Where: $\alpha_{0}=$ parameters to be estimated

$\alpha_{1} r=$ radio $; \alpha_{2} S p=$ sponsorship $; \quad \alpha_{3}$ Spromo $=$ sales promotion; $\quad \alpha_{4}$ TVep $=$ TV expenditure

$\varepsilon_{t}=$ error term

The apriory expectations are:

$\alpha_{1} r>0 ; \alpha_{2} S p>0 ; \alpha_{3}$ Spromo $>0 ; \alpha_{4} T V \exp >0 ;$

3.3 Data Type and Sources

An investigation was undertaken to establish whether the independent variables - marketing communication elements registered any significant effect on the dependent variable - sales. The qualitative approach was used to generate both the primary and secondary data. The demands of the present study made the use of secondary data very appropriate. The secondary data was considered cost-effective and easily accessible source of information compared to the primary data. The secondary data was obtained from both within and outside the organization. External secondary data are those collected from research findings including textbooks, journal articles, and 
reports. Internal secondary data is obtained from within the organization - sales documents, initiated surveys, annual reports, publication, minutes of meeting, newsletters, including service feedback and more. The overall advantage of secondary data in research is its flexibility, as it is often information that an individual researcher cannot collect on his or her own since it is already available.

In addition, the characteristics of both the descriptive and causal research strategies were equally useful in helping meet the varied requirements of the study. The main requirements included descriptive narrations of the tools of marketing communication including discussing the causes. Descriptive research helps describe the characteristics and scope of the problem, while the causal research determines which factors or variables are causing a particular behavior, (Malhotra \& Birks, 2006). The direct communication method was also opted for simply because of the key role that marketing communications play in modern business activities.

\section{Results and Discussion}

\subsection{Modelling Results}

In line with the Ifeanyi-Obe et al's (2008) study model which uses company data comprising records of sales budgets in evaluating the effect of marketing communications on sales to run a simple linear regression analysis to produce the following results, the model for this study is formulated as follows:

$$
S V=f(r, s p, \text { spromo }, T V \exp )
$$

Insert Table 2

From the table, the t-values of all the independent variables, with the exception of the sales promotion budget are insignificant. They therefore do not explicitly explain the variations in the dependent variable of total sales. On the other hand, the $\mathrm{F}$ - statistics (Prob $>\mathrm{F}=0.0000$ ) indicates that the variables are jointly significant in explaining the variations in the dependent variable (total sales). The R-Squared value of 0.79 indicates that about $79 \%$ of the variations in the total sales of the company are explained by the changes in the independent variables of marketing communications.

Sales promotion is found to have positive a relationship with total sales. This is indicated by the positive coefficient (.72). This means that if the sales promotion budget changed by a unit, the company's sales would increase by .72 . In practical terms, this indicates that sales promotion campaigns should induce positive outcomes on GT's (Vodafone) sales performance. For instance, between 2006 - 2008, when GT (Vodafone) decided to embark on intensive sales promotion campaigns aimed at boosting the usage of the mobile top-up cards, sales rose from $\mathrm{GH} \phi 2,283,843$ in 2005 , to $\mathrm{GH} \phi 6,514,687$ in 2006 , GHф8,946,787 in 2007, and to GH $\notin 9,320,602$ in 2008. This is consistent with Heerde et al's (2004) study conclusion that promotions resulted in increased sales of a firm's brands. The increase was attributed by the authors to the fact that when consumers switched brands and purchased earlier or more during promotions, it was bound to result in a rise in sales.

The results of this study also affirms that of Ifeanyi-Obe et al (2008) which evaluated the effect of sales promotion on the volume of sales of Royco from 1998 to 1999. The result from the findings of the research established a positive relationship between sales promotion and sales volume.

The study also revealed that a unit change in Radio Ad budget also resulted in a .0185 change in total sales. This is also consistent with a similar study by Doyle and Saunders (1990) which concluded that advertising does positively influence the sale of the brands of a firm, reflecting in its profits. Since GT's (Vodafone) sales promotion campaigns are always supported by Ads, their successes are more often than not linked together too. Thus it can be seen that Radio Ads helped GT (Vodafone) raise its sales volumes.

A positive relationship was also found to exist between DEL sales and total sales. The results indicated that a unit rise in DEL sales brought about .0309 units rise in total sales during the study period. A study of GT's DEL sales from 2006 to 2008 confirms this outcome. In 2006, 21,103 new lines were acquired. This increased to 24,667 in 2007 and rose further to 34,042 in 2008. These increases could be attributed to the launch of the internet service; Broadband (BB4U). The results also confirms the findings by Chauvin and Hirschey (1997) which employed marketing communications tools with various variables such as sales promotions, advertising, sales volumes and budget.

The current research also shows a positive relationship between BB4U sales and total sales. The results indicate that a unit rise in BB4U sales brings about .209 units rise in total sales during the study period. In 2007, 6,338 customers subscribed for BB4U facility, rising to 13,002 in 2008. This is also consistent with the findings by Erdem and Sun (2002) which maintained that advertising did not only influence the sales of the advertised products, but also the sales of related products (from the same company) which in our case are DEL and BB4U. 
This further affirms the findings that the communication effort of a firm has positive influence on the other brands of the same firm.

The relationship between sponsorship budget and total sales was however found to be negative. Even though, the major reason why companies such as GT (Vodafone) engage in sponsorship is to generate positive effects that would spill over to their brands, there are aspects of sponsorship that may give rise to negative cues that can be associated with a brand. A study recorded by Shimp (2000) provides evidence that challenges, whether Olympic sponsorships, represent a good return on investment. The study demonstrates that stock values declines following announcements of Olympic sponsorship. The reason is that analysts do not find this to be a good financial investment. In contrast, Harvey and Despain (2003) suggest that the sponsorship of a contest can cause audiences to be exposed, to increasing their willingness to buy the sponsor's product. This should however not be a surprise finding since that has always been the expectation which causes marketers to use sponsorship. They however concluded that marketers today remain unsure of how sponsorship works and how to properly measure its business value.

The results indicate also that TV Ad budget is negatively correlated with the total sales. The outcome indicates that a unit rise in TV Ad budget produced a .038 fall in total sales of GT (Vodafone). This means that in instances where customers do not own TV sets or follow through with advertisement on TV, spending on such marketing communications elements may bring negative returns to the firm. It is significant to note that the study indicates both positive and negative influence of GT's (Vodafone) marketing communications on its sales volumes. For instance, small increase in the marketing communications expenditure of some of the brands registered a significant increase in sales, while on the other hand a few negative responses are recorded.

\section{Conclusions and Recommendations}

The conclusions drawn from the study are that: GT (Vodafone) failed to institute the necessary structures to periodically measure, evaluate and review their marketing communications activities. They appear to be simply unaware of the relative effectiveness of each of elements and how best to integrate them together across the firm to help make better decisions. This is probably the most complicated challenge for GT (Vodafone). For instance, how much relative effect does each campaign have on sales volume as compared to the effect on the other elements of marketing communications. It is obvious that of all the decisions marketing managers make, those concerning promotional allocations are considered to be the most difficult and troublesome to measure. Several reasons account for this complexity. These reasons include:

- Obstacles in identifying an appropriate measure, or metric of effectiveness.

- Challenge with getting people throughout the organization to agree that a particular measure is the most appropriate.

-Difficulties encountered with gathering and assessing data impede the effective evaluation of marketing communications activities.

- Difficulties involved in determining the exact effect that each specific marketing communication element has on the measure selected to indicate effectiveness.

Apparently, GT (Vodafone) has no laid down policies culminating into factors strictly adhered to in the selection of marketing communications tools and its supporting budgets. Their choices are based on previous practices backed by the prevailing market conditions together with management discretion. It is evident too that the roles and responsibilities of the marketing communications, corporate communications and marketing overlap posing challenges to issues such as who does what and where does the role end. This could cause conflicts among the managers, giving rise to territorial divisions and culminating into power struggle that could tickle down to their subordinates. Besides, getting all managers in separate units to agree on a budget can become a big challenge to management. In addition, GT (Vodafone) has no significant commitment to Research and Development (R\&D) as far as its communications campaigns are concerned. From the interactions, there was no indication that the selections of GT's (Vodafone) marketing communications tools were based on any scientific considerations and procedures.

It is recommended that GT (Vodafone) considers first the environment within which it operates as the environmental forces (social, economic, political, competitive, etc) could serve as a guide to which communication elements are appropriate within the industry and provide a fair idea of profits from the campaigns. Management as well as other mobile network operators must particularly consider the competitive environment prevailing in the industry before making marketing communications decisions and commitments. Subsequently, managers should consider the internal environment - employees, departments as well as shareholders' needs. A careful examination 
of the company's current marketing strategies, policies and procedures would be appropriate in ensuring that they conform with all their communication mix; practically put, they must "walk the talk".

The most significant action for successful marketing communications is the integration of the marketing communications elements with other marketing activities in order to deliver a consistent message to consumers. It is understandable that well-executed communications programme often has many moving parts which makes it difficult to have a complete view of performance. Therefore management must include the appropriate evaluation/measurement criteria to any marketing communications programme design so that all components of the mix can be monitored to measure their business value. Also, GT (Vodafone) should also put in place measures to evaluate the effectiveness of their marketing communication mix which also involves obtaining feedback from the target audience. For example, whether they recognize or recall the communication, how many times they saw an advert for instance, what points they recall, how they felt about the communication, including their previous and current attitudes towards the product and the Company. It is also recommended that GT (Vodafone) pays more attention to personal selling and direct marketing. It is evident from the study that these two elements appear to be relegated to the background.

Finally, GT (Vodafone) should also draw a marketing communication policy based on its mission and vision statements. This would clearly specify both acceptable and unacceptable areas of activity. For instance, they may decide not to sponsor certain activities and events, (such as political activity) or individuals. In this case, all potential sponsorships that have successfully passed policy screening must be evaluated against selection criteria that have been predetermined. The same procedure could be set against the selection of the other tools of marketing communications.

\section{Limitations of the Study}

All research studies have potential weaknesses and just as all procedures have limitations. For this study, the main limitation was lack of relevant data to support the study coupled with time constraints. The major challenge faced during the study was GT's (Vodafone) unwillingness to divulge information on budget allocations on marketing communications activities that were considered very confidential and not meant for public consumption. Their reluctance was based on the fear that the information could land in the hands of its competitors and likely to affect their business operations. Besides, time constraints did not also offer the chance for the study to compare the budgetary allocations and sales of other service providers in the industry such as - MTN, Zain, Kasapa, and Tigo with GT (Vodafone).

\section{References}

Advertising Age. (2005). Advertising expenditure. [Online] Available: http//www. qed.princeton.edu/index.php/.../Advertising_expenditure,_1950-2005

American Marketing Association. (2008). Definition of Marketing. [Online] Available: http://www.marketingpower.com/AboutAMA/.../DefinitionofMarketing.aspx

Arens, W. F. (1999). Contemporary advertising. (7th ed.). New York: Irwin McGraw-Hill.

Blythe, J. (2006). Marketing. London: Sage Publications.

Chadwick, S., \& Thwaites, D. (2005). Managing sport sponsorship programs: Lessons from a critical assessment on English soccer. Journal of Advertising Research, 45, 328-338. http://dx.doi.org/10.1017/S0021849905050312

Chavrin, K.W., \& Hirschey, M. (1994). Goodwill profitability and the market value of the firm. Journal of accounting and public policy. Elsevier, 13(2).

Churchill, G. A. Jr., \& Peter, J. P. (1998). Marketing: Creating value for customers. New York: Irwin McGraw-Hill.

Cowell, D. W. (1994). The Marketing of services. Oxford: Butterworth-Heinemann Ltd.

Doyle, P., \& Saunders, J. (1990). Multiproduct advertising budgeting. Marketing Science, 9(2), 97-113. http://dx.doi.org/10.1287/mksc.9.2.97

Dubrin, A. J. (1997). Fundamentals of organizational behavior: An applied approach. Ohio: South-Western College Publishing.

Eberhard, U., \& Lenz, M. (2006). Make it real, strengthen brands, increase advertising efficiency Communication planning and professional campaign management in mobile telecommunications. Harlow: FT Prentice Hall. 
Erdem, T., \& Sun, B. (2002). An empirical investigation of spillover effects of marketing mix strategy in umbrella branding. Journal of Marketing Research, 39(4). 13-25. http://dx.doi.org/10.1509/jmkr.39.4.408.19120

Fahy, J., Farrelly, F., \& Quester, P. (2004). Competitive advantage through sponsorship: A conceptual model and research propositions. European Journal of Marketing, 38(8), 1013-1030. http://dx.doi.org/10.1108/03090560410539140

Ghana Telecom. (2005 - 2008). Annual Reports. Accra: Buck Press.

Grasby, E., Crossan, M., Frost, A., Haywood-Farmer, J., Pearce, M., \& Purdy, L. (2000). Business decisions: Text and cases. Ontario: Thomson Learning

Heerde, J.J.C., Leeflong, P., \& Wittink, D. (2004). Decomposing the sales promotion bump with store data. Marketing Science, 23(3), 317-334. http://dx.doi.org/10.1108/03090560410539140

Ifeanyi-Obe, J., \& Lemchi, B. I. (2008). Effect of sales promotion on the volume of agro-product (Royco). Journal of Agriculture and Social Research, 8(2).

Jobber, D. (2007). Principles and practice of marketing. Berkshire: McGraw-Hill.

Kotler, P. (1998). Marketing management - Analysis, planning, implementation, and control. (9th ed.). Englewood Cliffs: Prentice-Hall.

Kotler, P., \& Armstrong, G. (2010). Principles of marketing. (13th Global Edition). Englewood Cliffs: Prentice Hall.

Kotler, P., \& Keller, K. L. (2009). Marketing management. (13th Pearson International Ed.). Englewood Cliffs: Prentice Hall.

Kotler, P. (2006). Marketing Management. New Jersey: Person Education.

Lee, M., Sandler, D., \& Shani, D. (1997). Attitudinal constructs towards sponsorship. International Marketing Review, 14(3), 159-169. http://dx.doi.org/10.1108/02651339710170230

Malhotra, N., \& Birks, D. (2006). Marketing research: An applied approach. New Jersey: Pearson Education Ltd

Mcshane, S. L., \& Glinow, V. (2000). Organizational behavior. New York: Irwin/McGraw Hill.

Palmer, A. (2005). Principles of service marketing. (4th ed.). Berkshire: McGraw-Hill Education

Smith, P., Berry C., \& Pulford, A. (1997). Strategic marketing communications. London: Kogan Page Ltd.

Stotlar, D. (2004). Sponsorship evaluation: Moving from theory to practice. Sport Marketing Quarterly, 13, 61-64.

Sturgess, B., \& Young, R. (1981). The sales response to advertising, a reconsideration. Managerial and Decision Economics, 3(2). John Wiley and Sons. 
Table 1. Promotion schedule

\begin{tabular}{|c|c|c|c|c|}
\hline Period & $\begin{array}{c}\text { Normal Sales } \\
\text { GH } \phi\end{array}$ & $\begin{array}{c}\text { Promotional Sales } \\
\text { GH } \phi\end{array}$ & $\begin{array}{c}\text { Incremental } \\
\text { Contribution GH } \phi\end{array}$ & $\begin{array}{c}\text { Percentage } \\
\text { Increase }\end{array}$ \\
\hline March 2006 & 217,508 & 254,100 & 36,192 & 17 \\
\hline June 2006 & 237,108 & 292,400 & 55,292 & 23 \\
\hline Sept 2006 & 256,308 & 332,560 & 762,514 & 30 \\
\hline Dec 2006 & 275,508 & 325,240 & 497,320 & 18 \\
\hline January 2007 & 986,332 & $1,204,299$ & 217,967 & 22 \\
\hline
\end{tabular}

Source: Ghana Telecom Sales Report (2007)

\begin{tabular}{|l|c|}
\hline Incremental contribution from increased usage (in GHф) & $2,174,661$ \\
\hline Less: & \\
\hline Media & $1,676,385$ \\
\hline Prizes - vehicles & 230,000 \\
\hline Subtotal & $\mathbf{1 , 9 0 6 , 3 8 5}$ \\
\hline Less: Normal TV/Radio/Press without promotions & 70,000 \\
\hline Total cost due to promotions & $\mathbf{1 , 8 3 6 , 3 8 5}$ \\
\hline
\end{tabular}

Table 2. The regression output

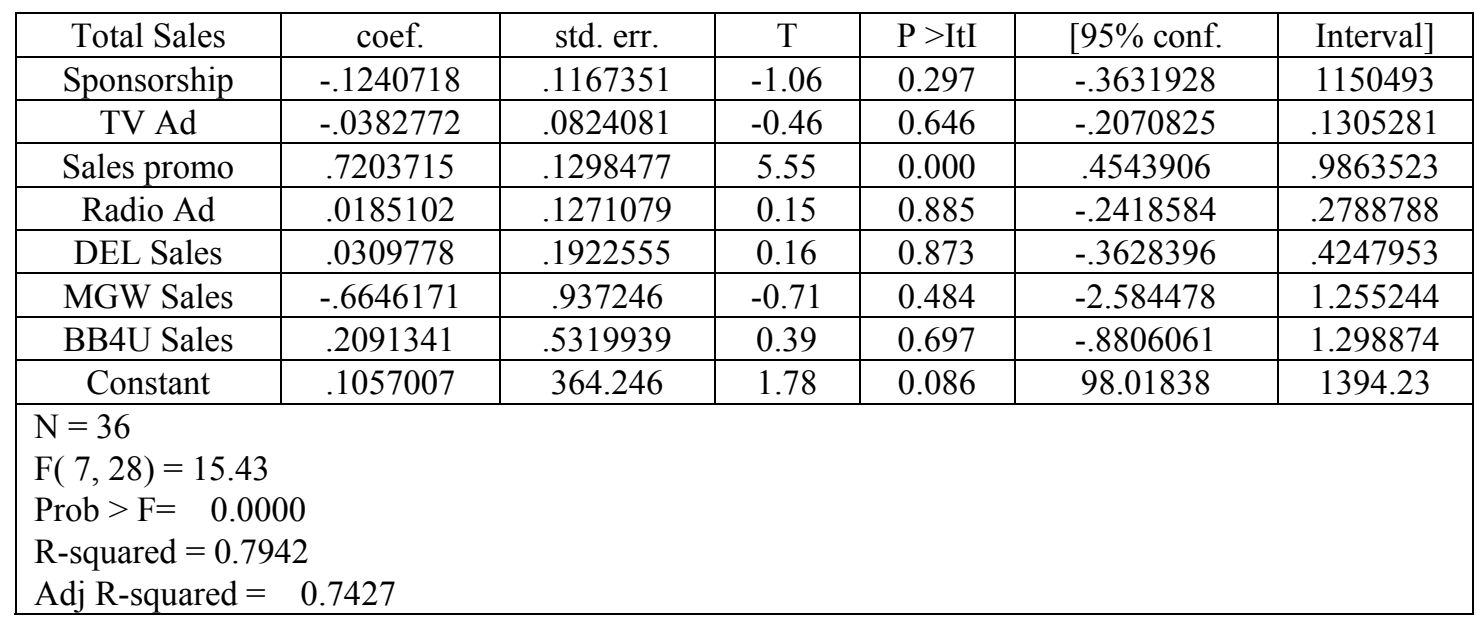




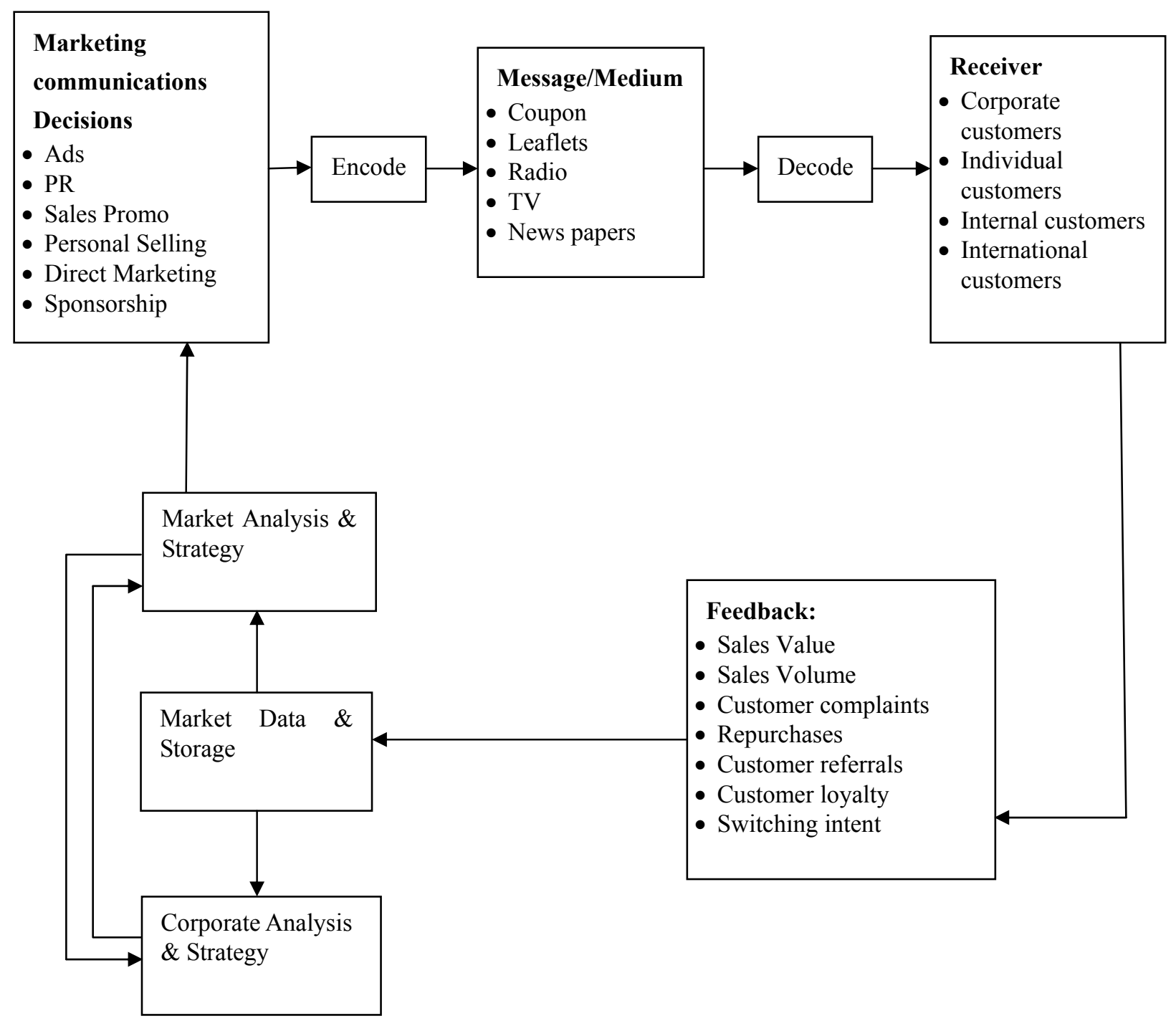

Figure 1. The relationship between marketing communications and business strategy Source: Adapted and Modified from Smith, Berry and Pulford (1997) 